\title{
Estudio teórico de SFRP1 como nueva diana terapéutica para el tratamiento del Alzheimer.
}

\author{
Laura Carrasco-Rubio ${ }^{a}$, Eulalia González-Carrión ${ }^{\mathbf{b}}$, Javier Martínez-del-Ríoc, Irene Martínez- \\ Pasabados $^{\mathrm{d}}$
}

Departamento de Biología de Sistemas, Facultad de Medicina, Universidad de Alcalá (UAH). Alcalá de Henares (Madrid).

\begin{abstract}
a. lauralcr20@hotmail.com; Icrlaura20@gmail.com b. laligonzalezc16@gmail.com c. javier.mzdr@gmail.com d. martinezpasabadosirene@gmail.com
\end{abstract}

Palabras clave: enfermedad de Alzheimer; SFRP1; ADAM10; drug discovery project

\section{Resumen}

La enfermedad de Alzheimer (EA) es una enfermedad neurodegenerativa del sistema nervioso central caracterizada por una muerte progresiva neuronal que afecta principalmente a regiones corticales del cerebro y parte del sistema límbico. Se producen alteraciones en la memoria, el lenguaje, la percepción, la orientación y las funciones ejecutivas, siendo una de las principales causas de demencia en el mundo. Una de las principales características de la EA es la aparición de placas seniles o amiloides. Las placas seniles son depósitos extra-neuronales conformados por la acumulación del péptido $A \beta-42$ (péptido $\beta$ amiloide), producido por la proteólisis de la proteína precursora amiloide (APP) por $\beta$-secretasa y $\gamma$ secretasa. En cambio, la escisión no patológica de APP se produce por $\alpha$-secretasa y y-secretasa. Se prevé que la EA afecte a más de 150 millones de personas para 2050, convirtiéndose en un problema socioeconómico grave. Pese a todos los esfuerzos, aún no se ha conseguido ninguna terapia efectiva. Debido a la ineficacia en las terapias contra las dianas terapéuticas conocidas actualmente, en el presente trabajo hemos investigado la proteína SFRP1 como una nueva diana terapéutica potencial. SFRP1 se encuentra sobre-expresada en pacientes con EA produciendo inhibición de ADAM10 ( $\alpha$ secretasa), favoreciendo la formación del péptido $\beta$-amiloide. Hemos desarrollado, de forma teórica, un proyecto para conseguir compuestos que inhiban SFRP1 e impidan su unión a ADAM10, de forma que esta a-secretasa pueda realizar su función. Para este proyecto teórico asumimos que disponemos de una librería con numerosos compuestos químicos a partir de la cual diseñamos un proceso de drug discovery con el objetivo de conseguir un compuesto con capacidad de inhibir a SFRP1 cuyas propiedades permitan su uso como fármaco. Para ello hemos desarrollado un pre-cribado computacional y un posterior ensayo de alto rendimiento (HTS) mediante FRET. Este ensayo nos permitiría identificar qué compuestos cuentan con un mayor porcentaje de inhibición y serían re-evaluados con ensayos HTS para seleccionar aquellos con menor IC-50 y mayor selectividad frente a SFRP1. A continuación, se evaluarán mediante un ensayo PAMPA los compuestos con capacidad para atravesar la barrera hematoencefálica y se realizarán estudios in vitro en células telencefálicas e in vivo en modelos de murinos de EA para confirmar su eficacia. Por último, se desarrollarían estudios pre-clínicos de farmacología y toxicología de los compuestos seleccionados, como paso previo al estudio del fármaco en ensayos clínicos para comprobar si finalmente podría usarse como tratamiento de la EA.

Cita: Carrasco-Rubio, Laura; González-Carrión, Eulalia; Martínez-del-Río, Javier; Martínez-Pasabados, Irene (2020) Estudio teórico de SFRP1 como nueva diana terapéutica para el tratamiento del Alzheimer. Actas del V Congreso de Señalización Celular, SECUAH 2020. Departamento de Biología de Sistemas, Facultad de Medicina, Universidad de Alcalá (UAH). Alcalá de Henares, Madrid (Spain). dianas 9 (1): e202003fa01. ISSN 1886-8746 (electronic) journal.dianas.e202003fa01 http://www3.uah.es/dianas?e202003fa01.

URI http://hdl.handle.net/10017/15181

Copyright: (c) Carrasco-Rubio L, González-Carrión E, Martínez-del-Río J, Martínez-Pasabados I. Algunos derechos reservados. Este es un artículo open-access distribuido bajo los términos de una licencia de Creative Commons Reconocimiento-NoComercial-SinObraDerivada 4.0 Internacional.

http://creativecommons.org/licenses/by-nc-nd/4.0/

\section{Introducción al Alzheimer y principales características}

En 1906 Alois Alzheimer describió una nueva entidad patológica con dos características anatomopatológicas distintivas presentes en el cerebro: las placas seniles amiloides y los ovillos neurofibrilares. Esta patología pasó a denominarse Enfermedad de Alzheimer.

La EA es una enfermedad neurodegenerativa del Sistema Nervioso Central (SNC) caracterizada por una muerte progresiva neuronal que afecta principalmente a regiones corticales del cerebro y parte del sistema límbico (Moya, 2014). Inicialmente se detecta por fallos en memoria, a los que siguen alteraciones en el lenguaje, en la percepción, orientación, en la memoria (Moya, 2014; Crespo, 2015) o en las funciones ejecutivas, siendo una de las principales causas de demencia en el mundo (Esteve et al., 2019b). 
Actualmente se conoce que existen dos características neuropatológicas fundamentales en la EA, las placas seniles o amiloides y los ovillos neurofibrilares (Moya, 2014):

a) Las placas seniles son depósitos extraneuronales formados por la acumulación del péptido Aß-42, lípidos, proteínas y metales libres. Podrían actuar como reservorios de los oligómeros bioactivos contribuyendo a la pérdida de las sinapsis y a la muerte neuronal en humanos a lo largo del curso de la enfermedad, detectando un adelgazamiento del tejido nervioso en los pacientes con EA (Crespo, 2015).

b) Y los ovillos neurofibrilares son depósitos intraneuronales de proteína TAU, la cual estabiliza los microtúbulos axonales (Moya, 2014).

Existen dos formas de EA: 1) La forma familiar y genética, poco frecuente (afecta aproximadamente al $5 \%$ de los pacientes, a pesar del componente ambiental, la heredabilidad está entre el 60-80\%) y de aparición temprana (antes de los 65 años). Se caracteriza por la presencia de mutaciones en los genes $A P P, P S 1$ y $P S 2$ (presenilina 1 y 2) (Crespo, 2015). 2) Y una forma esporádica o de inicio tardío, en la que la gran mayoría síntomas aparecen más tardíamente y donde la edad es el mayor factor de riesgo. El origen es desconocido y seguramente multifactorial (factores de predisposición genética, síndrome metabólico, hábitos dietéticos o inflamación periférica) (Crespo, 2015). Se prevé que para 2050, la EA esporádica afectará a 150 millones de personas en todo el mundo, convirtiéndose en un problema socioeconómico insostenible (Esteve et al., 2019b).

\section{Hipótesis sobre la EA}

En la actualidad, se desconoce el mecanismo que provoca la muerte neuronal, aunque se plantean diversas posibilidades que llevan a una alteración de las cascadas de señales intracelulares y cambios metabólicos (González, 2010):

Estrés oxidativo: En la EA se ha observado que hay un aumento de ROS (Especies Reactivas de Oxígeno) y RNS (Especies Reactivas de Nitrógeno) y una reducción de enzimas antioxidantes. Esta situación lleva a una oxidación de proteínas y ácidos nucleicos y la peroxidación de lípidos de las placas de péptido $\beta$-amiloide como en las neuronas. El hecho de que los síntomas de la EA mejoran con el tratamiento del estrés oxidativo apoya la hipótesis de que éste actúa como mecanismo patogénico de esta enfermedad. Se ha demostrado que dicho estrés precede a la formación de las neurofibrillas y las placas seniles, ya que sus lesiones aparecen también en neuronas sin placas ni ovillos neurofibrilares (González, 2010).

Hipótesis TAU: En EA, la hiperfosforilación anormal de la proteína TAU, producida por una hiperactivación de sus kinasas debido a un aumento de $\mathrm{Ca} 2+$, hace que TAU se apelmace formando los ovillos neurofibrilares y pierda su capacidad para estabilizar los microtúbulos (Moya, 2014) (Figura 1) y adquiriera una función tóxica, provocando la desestabilización del citoesqueleto y la degeneración neuronal. Además, se ha observado que en la EA se produce alrededor de un $20 \%$ de descenso de la actividad de las proteínas fosfatasas responsables de su desfosforilación (PP-1 y PP-2A) agravando aún más el problema (González, 2010).
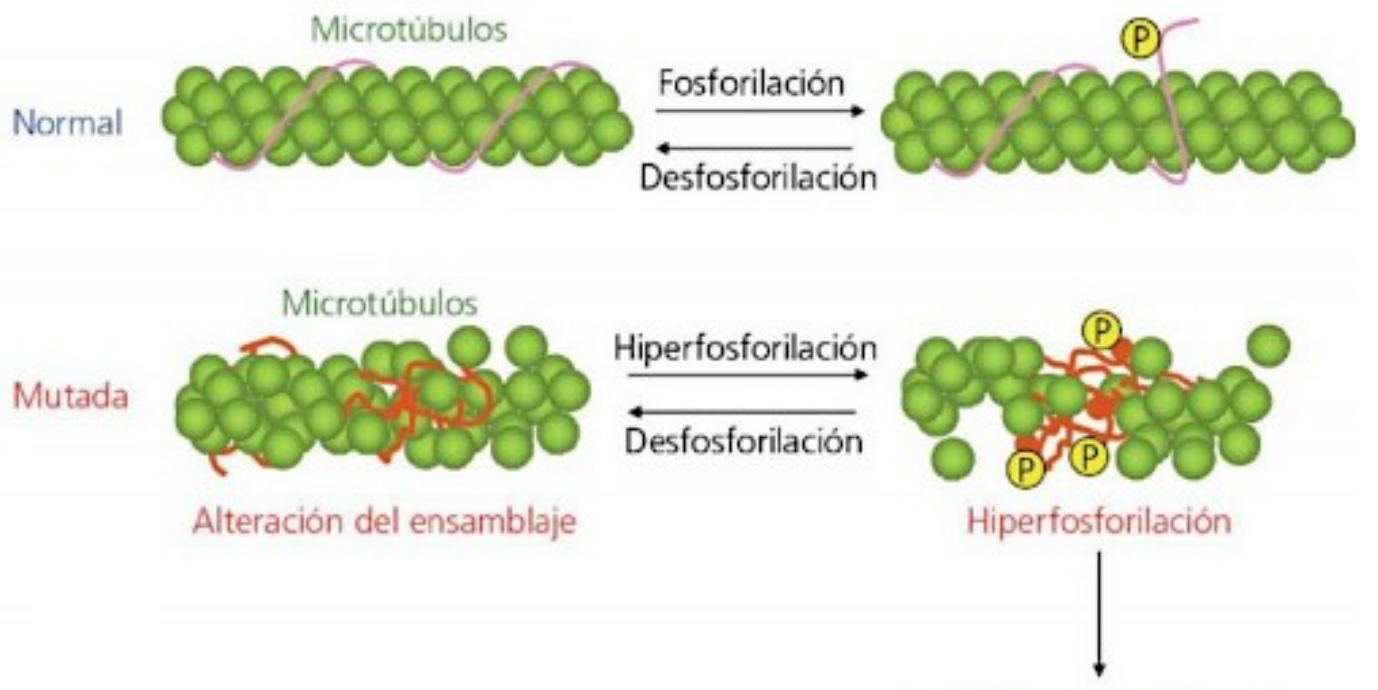

B

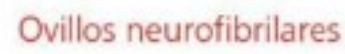

Figura 1: La proteína TAU se encuentra estabilizando los microtúbulos y tiene una fosforilación reversible. La mutación de la proteína TAU causa alteraciones en la unión a microtúbulos e hiperfosforilación, lo que favorece que las proteínas formen ovillos neurofibrilares (González 2010). 
Placas de amiloide: La proteína precursora de amiloide es una glucoproteína transmembrana codificada por el gen APP, localizado en el cromosoma 21. Esta proteína es indispensable para el crecimiento de las neuronas, para su supervivencia y su reparación postdaño. Tras la síntesis, ésta se glucosila, fosforila y posteriormente se ancla en la membrana. La APP anclada en membrana sufre un corte proteolítico extracelular por las enzimas $\alpha$ o $\beta$-secretasas, y el fragmento remanente en la membrana sufre posteriormente la proteólisis por acción de la $\gamma$-secretasa. Así pues, hay dos tipos de proteólisis: a) Una proteólisis no amiloidogénica, por la $\alpha$ y $\gamma$-secretasas, que producen los péptidos $\alpha$-APP y p3 (Figura 2). b) Una proteólisis amiloidogénica, por la $\beta$ y $\gamma$-secretasas, en la cual se producen los péptidos $\beta$-APP y A $\beta$. El tamaño del péptido A $\beta$ más común es de 40 aminoácidos, por lo que se le denomina $A \beta-40$, y una pequeña proporción $(10 \%)$ es de 42 aminoácidos, el $A \beta-42$. Este péptido $A \beta$ se va eliminando por unas peptidasas (la neprilisina, la enzima degradadora de insulina o la plasmina) y por transporte mediado por receptores (González, 2010).

Las $\alpha$ y $\beta$ secretasas compiten por el mismo sustrato, así una mayor actividad de $\alpha$-secretasa (ADAM10) favorece la generación de $\alpha$ APP y reduce la del péptido A $\beta$ (Crespo, 2015). Las mutaciones que disminuyen la actividad de las $\alpha$-secretasas, desplazan el procesamiento de APP hacia la vía proamiloidogénica, se relacionan con algunos casos de EA. Esto plantea la posibilidad de que el deterioro de la actividad de ADAM10 puede estar entre los desencadenantes comunes de la deposición amiloide, contribuyendo a la patogénesis de la EA (Esteve et al., 2019b).

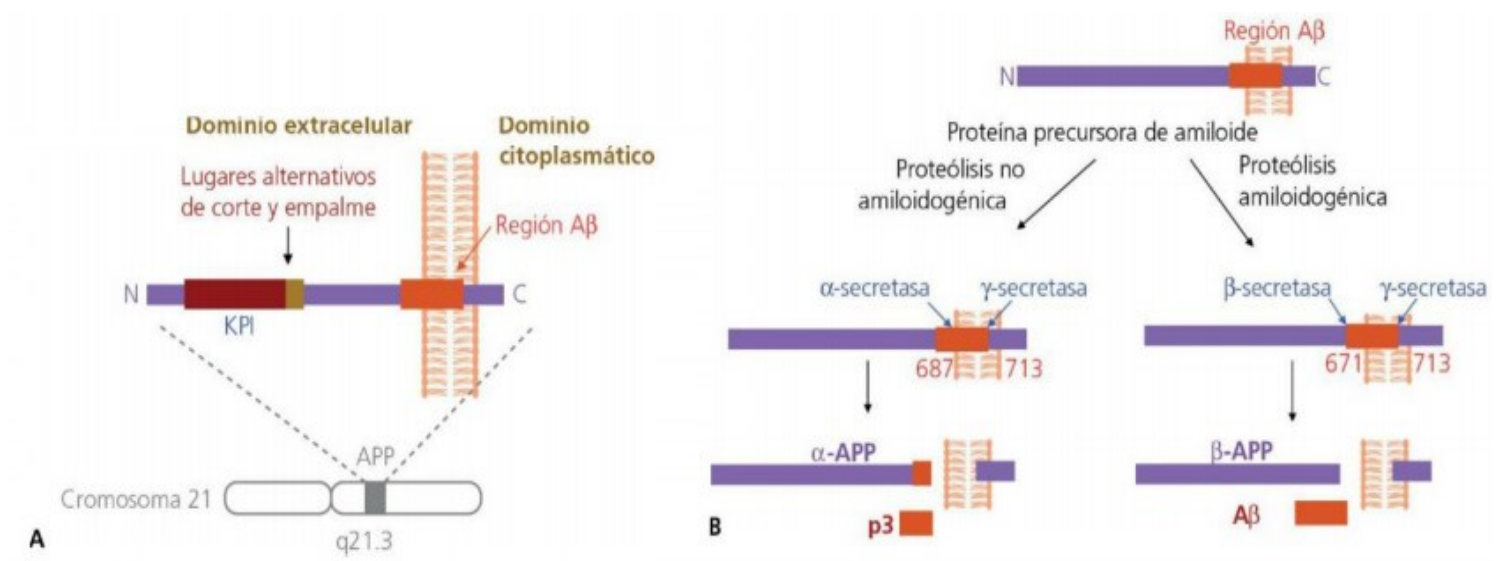

Figura 2: A. Localización del gen APP que codifica la proteína precursora amiloide y estructura de ésta. B. Procesamiento de la proteína precursora amiloide mediante las secretasas. KPI: inhibidor de proteasas de tipo Kunitz (del inglés, Kunitz-type protease inhibitor) (González, 2010).

Según la hipótesis de la cascada amiloide la presencia exacerbada del péptido $\beta$ amiloide (A $\beta$ ) es la causa primaria de la EA siendo el resto de las alteraciones (formación de ovillos neurofibrilares o daños sinápticos) resultado de un fallo en el balance de producción, agregación y/o eliminación del péptido A $\beta$. Aunque no esté totalmente demostrada la naturaleza causal de la hipótesis amiloidea, las placas de $\beta$ amiloide se relacionan con la EA. Por tanto, puede ser de gran utilidad estudiar el mecanismo que regula la generación del péptido A $\beta$ a partir de APP, así como las posibles variables relacionadas con dicho mecanismo (Crespo, 2015).

Debido a la importancia de esta enfermedad, en numerosos ensayos clínicos se han explorado agentes que podrían no sólo interferir con la fisiología de la enfermedad sino también proporcionar una mejora sintomática a corto plazo. Sin embargo, hasta la fecha ninguno de los tratamientos modificadores de la EA ha alcanzado la aprobación regulatoria (Elmaleh et al., 2019) (Figura 3).

Una de las estrategias ha sido la reducción o bloqueo de las diferentes formas del péptido $\mathrm{A} \beta$, y esto parece retrasar la enfermedad en modelos animales y frenar el declive clínico en pacientes con EA prodrómica o leve. Desafortunadamente, la enfermedad no se detiene, quizás porque los factores que favorecen la producción de amiloide- $\beta$ y desencadenan su agregación en formas tóxicas aún no se comprenden completamente (Esteve et al., 2019b). Ensayos clínicos con anticuerpos destinados a neutralizar el péptido $A \beta$ han fracasado o producen sólo un efecto reducido, aunque los últimos datos presentados con los fármacos solanezumab ${ }^{\circledR}$ y aducanumab ${ }^{\circledR}$ suponen un cierto optimismo prudente (Crespo, 2015).

Pese a todos los esfuerzos aún no se observan terapias efectivas, se han realizado más de 400 pruebas de más de 200 fármacos con una tasa de fracaso del 99,6\% (tasa de éxito de sólo el 0,4\%) (Elmaleh et al., 2019). Posiblemente este efecto tan limitado se deba a una intervención demasiado tardía. Ya que se ha descrito que pacientes con EA familiar, presentan cambios en distintos biomarcadores bioquímicos (péptido A 342 y la proteína Tau) en el LCR, depósitos amiloideos cerebrales y modificaciones en el metabolismo de la glucosa, entre 15 y 10 años antes de la aparición de los síntomas. Lo que sugiere un 
importante desfase temporal entre las alteraciones bioquímicas/anatómico-patológicas y las funcionales, indicando una progresión lenta de la enfermedad (Crespo, 2015).

En la búsqueda de una nueva diana terapéutica para la enfermedad de Alzheimer se ha encontrado SFRP1. Se ha descubierto que los niveles elevados de SFRP1 contribuyen a la patogénesis de la enfermedad de Alzheimer. (Esteve et al., 2019b)

\section{Alzheimer's Drug Development Pipeline}

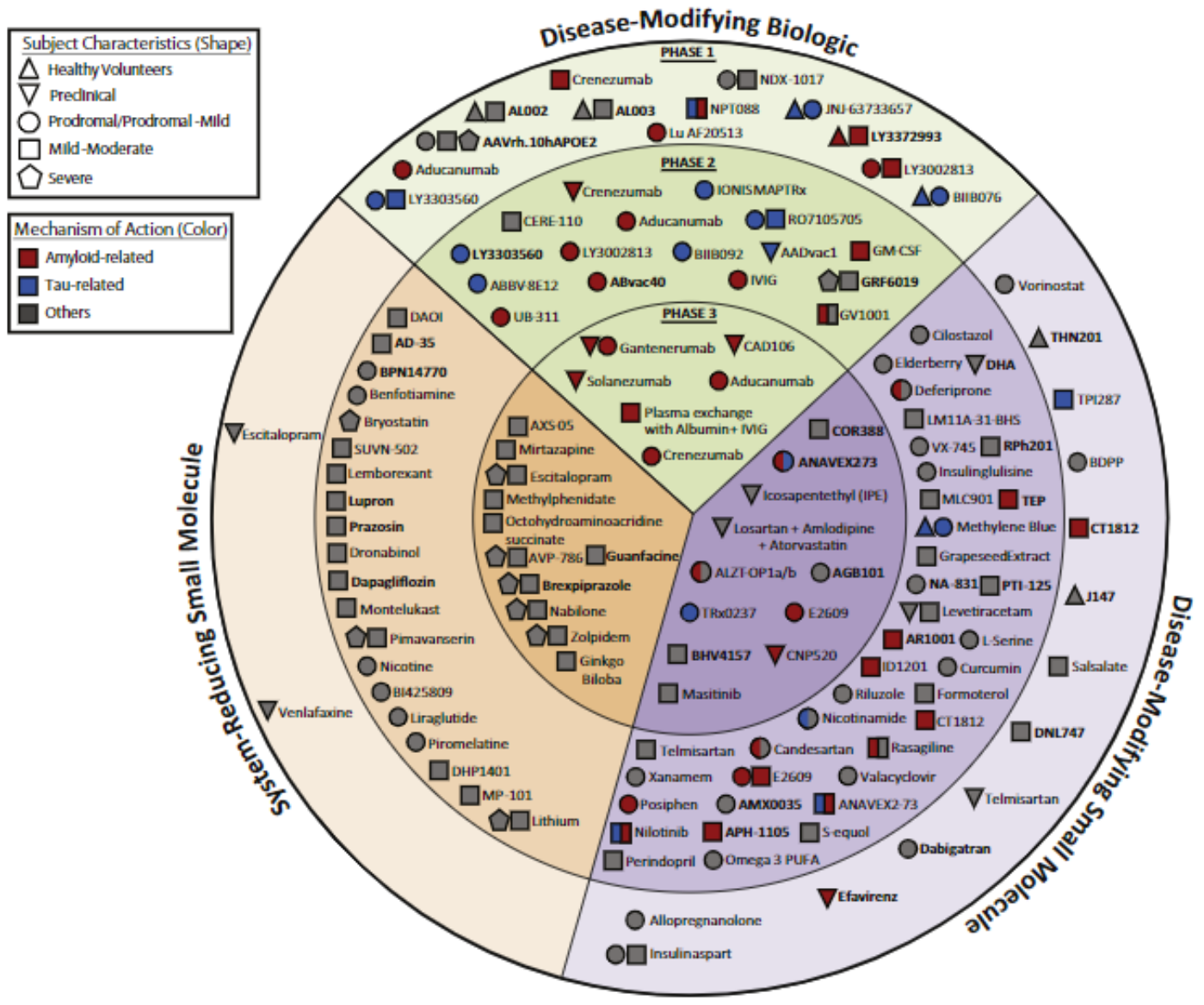

Figura 3: Todos los compuestos que se encontraban dentro de ensayos clínicos el 12 de febrero del 2019 (el anillo central muestra los compuestos que se encontraban en fase 3; el anillo del medio presenta los que se encontraban en fase 2; el anillo del exterior muestra los compuestos que se encontraban en fase 1; los agentes en el área de color verde son biológicos; los que se encuentra en áreas de color morado son pequeñas moléculas que modifican la enfermedad; los que están dentro de zonas naranjas son agentes sintomáticos que abordan mejoras cognitivas o síntomas conductuales y neuropsiquiátricos; la forma del icono muestra la población del ensayo; el color del icono muestra el tipo de diana que tiene el agente.). Los nombres en negrita representan agentes nuevos en esa fase desde 2018 (Cummings et al., 2019).

\section{Estructura de SFRP1}

SFRP1 (Secreted Frizzled Related Protein 1) es miembro de una familia de proteínas secretables implicadas en el desarrollo embrionario y en la homeostasis celular del cerebro adulto (SFRPs).

Las SFRPS son proteínas de unos 36 kDa. Son moléculas solubles implicadas en la modulación de la apoptosis y como antagonistas de Wnt durante el desarrollo embrionario. En mamíferos esta familia está formada por cinco miembros, y se subdivide en dos subgrupos formados por SFRP1, 2, y 5 por un lado y SFRP3, 4 por el otro, con un posible origen evolutivo diferente.

El gen SFRP1 está formado por tres exones que codifican una proteína de alrededor de 314 aminoácidos donde más del $90 \%$ de los aminoácidos están conservados entre rata, ratón y humano. SFRP1, al igual que SFRP2 y 5 , está formada por dos motivos, codificados por el primer y tercer exón respectivamente, que se pliegan de forma independiente.

El extremo N-terminal contiene: un péptido señal que permite su secreción y $\mathrm{n}$ dominio rico en cisteínas (CRD), concretamente 10 cisteínas que forman 5 puentes disulfuro cuyo patrón está conservado entre los distintos SFRPs (Figura 4). Este dominio es homólogo a la parte extracelular de los receptores Frizzled (Fz) responsable de la unión de ligandos Wnt, razón por la que se los identificó como antagonistas de Wnt. (Crespo, 2015) 
Comprende los aminoácidos 53-169:

\section{TKPPQCVDIPADLRLCHNVGYKKMVLPNLLEHETMAEVKQQASSWVPLLNKNCHAGTQVFLCS LFAPVCLDRPIYPCRWLCEAVRDSCEPVMQFFGFYWPEMLKCDKFPEGDVCIAM (www.uniprot.org)}

El dominio C-terminal se caracteriza por presentar un segmento rico en residuos hidrofóbicos y 6 cisteínas que forman un patrón de 3 puentes disulfuro, denomina dominio NTR (Netrin-related motif) (Figura 4). Este dominio está presente en proteínas con funciones muy distintas, como netrina y los inhibidores de metaloproteinasas TIMPs (Crespo, 2015)

Comprende los aminoácidos 186-306:

CPPCDNELKSEAIIEHLCASEFALRMKIKEVKKENGDKKIVPKKKKPLKLGPIKKKDLKKLVLYL KNGADCPCHQLDNLSHHFLIMGRKVKSQYLLTAIHKWDKKNKEFKNFMKKMKNHEC (www.uniprot.org)

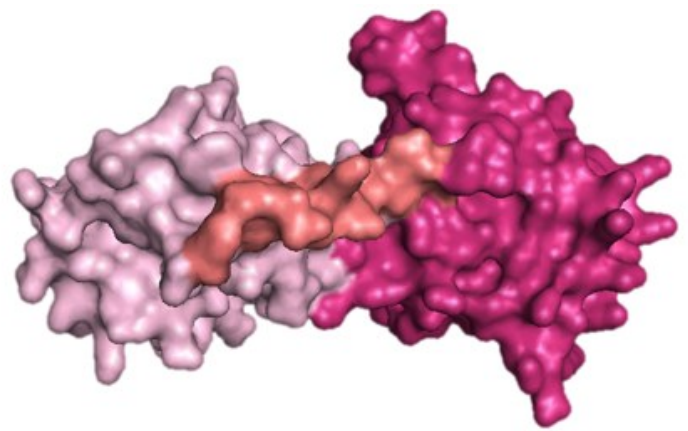

Figura 4: Representación tridimensional de SFRP1. En color rosa claro aparece representado el dominio CRD, mientras que en color rosa oscuro aparece representado el dominio NTR.

La expresión de Sfrp1 en mamíferos es alta en el cerebro, riñón, ojo, bazo, abdomen, corazón y somitas. La expresión del ARNm de SFRP1 en cerebro va disminuyendo desde las etapas embrionarias hasta la edad adulta y se incrementa en situaciones neuropatológicas como en enfermedad de Alzheimer, participando en esta enfermedad.

\section{Funciones de SFRP1}

Desde la identificación de SFRP1 se ha descrito que esta proteína, además de presentar funciones dependientes de Wnt, tiene capacidad para unirse a los receptores Fz, interactuar e inhibir la actividad de RANKL (una proteína asociada a la formación de osteoclastos), unirse a trombospondina 1 previniendo la adhesión celular y modular negativamente la actividad de ADAM10, lo que amplía considerablemente el espectro de sus actividades. Por ello, SFRP1 es una proteína multifuncional con distintos mecanismos de acción. (Crespo, 2015)

En este estudio nos centramos en profundizar el estudio en la modulación que ejerce SFRP1 sobre la vía Wnt/ $\beta$-catenina y ADAM10 en el sistema nervioso debido a la implicación de ambas en la enfermedad de Alzheimer.

\section{Implicación de SFRP1 en Alzheimer}

Estudios previos en pacientes con EA y en un modelo de amiloidosis en ratones apoyan un modelo en el que SFRP1, producido y secretado por microglía activada, astrocitos reactivos y células del plexo coroideo, se difunde en el parénquima cerebral para interferir en el procesamiento de APP mediada por ADAM10 en las neuronas, mejorando así el procesamiento de APP pro-amiloidógena y, por lo tanto, la producción de productos tóxicos de $\beta$-amiloide.

SFRP1 se acumula en las placas amiloides, forma agregados moleculares e interactúa con los péptidos $\beta$ amiloide, limitando la formación de protofibrillas Aß1-42 y favoreciendo la presencia de formas oligoméricas. Las formas oligoméricas de péptidos $\beta$-amiloide son tóxicas para las neuronas, mientras que se cree que las formas protofibrilares son menos dañinas.

La formación y agregación de $\beta$-amiloide contribuye además a activar las células gliales y, por lo tanto, a una mayor producción de SFRP1, sugiriendo que SFRP1 es parte del mecanismo de alimentación que sostiene la patogénesis de la EA.

En los pacientes con EA los niveles de SFRP1 se correlacionan positivamente con la cantidad de $\beta$ amiloide soluble.

Además, la inactivación genética del ADAM10 perjudica el aprendizaje y la memoria. 
Se ha demostrado que el aumento de los niveles de SFRP1 en los cerebros de los pacientes con EA podría mejorar el procesamiento de la APP pro-amiloidógena y la cascada de alteraciones cerebrales estereotipadas que, además del depósito de $\beta$-amiloide, incluyen la disfunción sináptica, la inflamación cerebral y la formación de neuritas distróficas, entre otras. Combinando estudios en casos de EA en humanos y en modelos de ratones, se ha demostrado que el SFRP1 está implicado en la patogénesis de la EA. La neutralización de la actividad del SFRP1 mediada por anticuerpos es suficiente para prevenir la disfunción sináptica, lo que apunta a una nueva vía terapéutica digna de ser explorada. (Esteve et al., 2019b)

\section{SFRP1 y vía WNT}

En ausencia del ligando Wnt, $\beta$-catenina es fosforilada y degradada vía proteosoma. Sin embargo, cuando el ligando Wnt se une al receptor Fz se destruye el complejo de fosforilación por lo que $\beta$-catenina se acumula en el citoplasma y transloca al núcleo donde activa la transcripción de genes dianas de la vía (Figura 5). (Crespo, 2015)

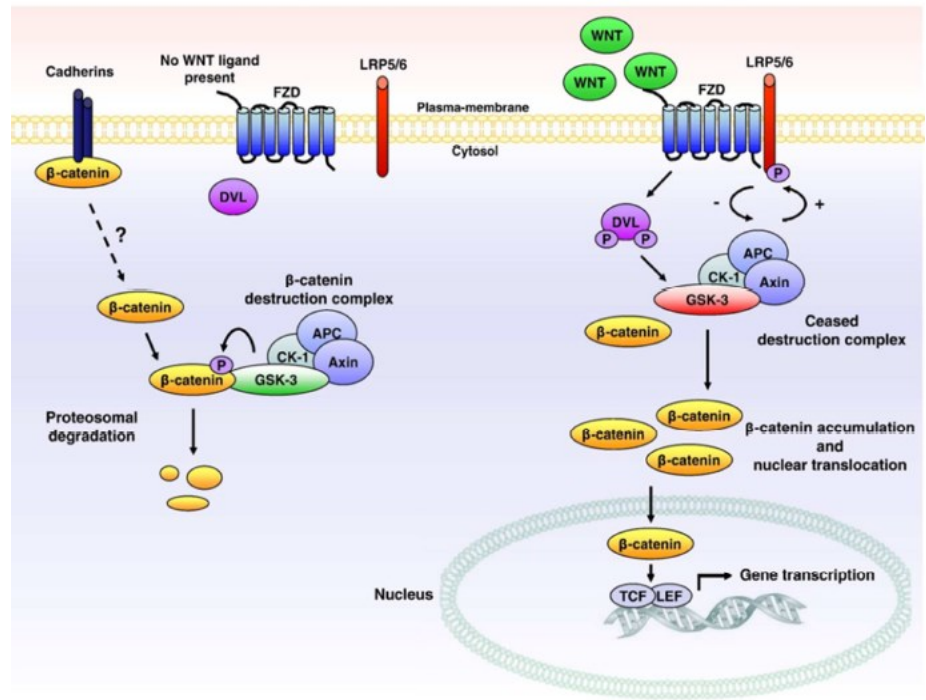

Figura 5: Mecanismo de acción de la vía canónica Wnt/ $\beta$-catenina. (Crespo, 2015)

Se ha visto que la sobreexpresión de la vía Wnt reduce la actividad y expresión de BACE1 y, por tanto, reduce los niveles de péptido $\beta$-amiloide. Debido a esto, se ha propuesto que la inhibición de la vía Wnt puede ser un nuevo tratamiento para enfermedad de Alzheimer. (Parr et al., 2015) Por ello, en este proyecto estudiamos la posibilidad de utilizar SFRP1 como diana terapéutica para poder inhibir la vía Wnt.

El dominio CRD es responsable de la unión de SFRP1 a Wnt, (Crespo, 2015), pero hay estudios que también han demostrado que el dominio NTR se puede unir a Wnt y hay evidencias de que ambos dominios se requieren para la inhibición óptima de Wnt. (Rueda, 2017)

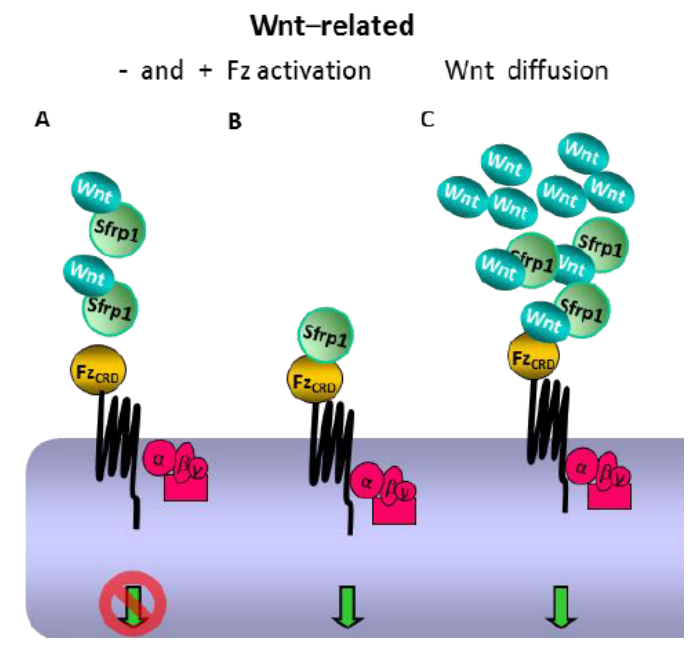

Figura 6: Modulación de SFRP1 sobre la vía Wnt. A) SFRP1 interacciona con Wnt e inhibe la vía Wnt. B) SFRP1 interacciona directamente con el receptor Fz e induce la activación de la vía Wnt. C) La interacción entre SFRP1 y Wnt produce la difusión de Wnt (Rueda, 2017) 
Aunque los ensayos de sobre-expresión de SFRP1 indican que esta proteína tiene un papel como antagonista de la vía de Wnt, ensayos de falta de función sugieren en muchos casos mecanismos de acción alternativos. SFRP1 actúa como una molécula bifásica dependiendo del contexto celular y de su concentración: concentraciones bajas de SFRP1 aumentan la actividad transcripcional mediada por $\beta$ catenina, mientras que concentraciones altas inhiben dicha actividad. Es un efecto dosis-respuesta. SFRP1 podría tener dos sitios de unión para Wnt con diferentes afinidades o alternativamente SFRP1 podría unirse a Wnt en bajas concentraciones y a Fz en altas concentraciones. A pesar de que los estudios de sobreexpresión y falta de función indican distintos modos de actuación sobre la vía de Wnt, la función fisiológica de SFRP1 parece depender del contexto celular y su función puede estar ligada también a otras vías de señalización y mecanismos de actuación (Figura 6). (Crespo, 2015)

Sin embargo, en ratones con inactivación de SFRP1, no se observaron cambios en la activación de la vía Wnt en cerebro respecto a ratones de tipo salvaje. Por tanto, SFRP1 in vivo parece independiente de su papel adicional establecido como modulador de la señalización Wnt. (Esteve et al., 2019b)

Por tanto, la inhibición de SFRP1 probablemente no afectará a la vía Wnt. Esto puede ser debido a que haya participación de otras proteínas que compensen la modificación de SFRP1 en la vía Wnt.

Por ello, no centramos nuestro estudio en la inhibición de la vía Wnt utilizando SFRP1 como diana terapéutica.

\section{SFRP1 como modulador negativo de la actividad proteolítica de ADAM10}

SFRP1 regula la actividad proteolítica de ADAM10.

ADAM10 es una proteína que pertenece a la familia de las desintegrinas y metaloproteinasas (ADAMs). ADAM10 es la $\alpha$-secretasa constitutiva por excelencia en neuronas primarias, está anclada a membrana y tiene actividad proteolítica sobre proteínas de membrana liberando el ectodominio de dichas proteínas al espacio extracelular.

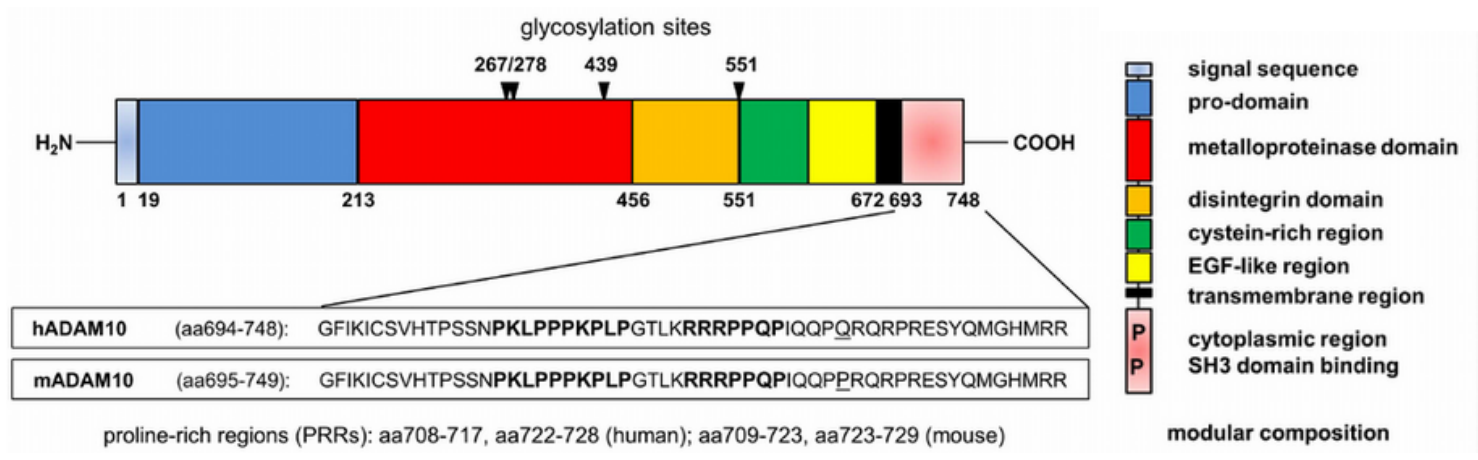

Figura 7: Representación esquemática de la estructura en dominios de ADAM10. (Ebsen et al., 2014)

\section{Estructura de ADAM10}

ADAM10 está compuesta de 770 aminoácidos en humanos, con una estructura conservada formada por varios dominios y se expresa de forma ubicua en el embrión y el adulto (Crespo, 2015).

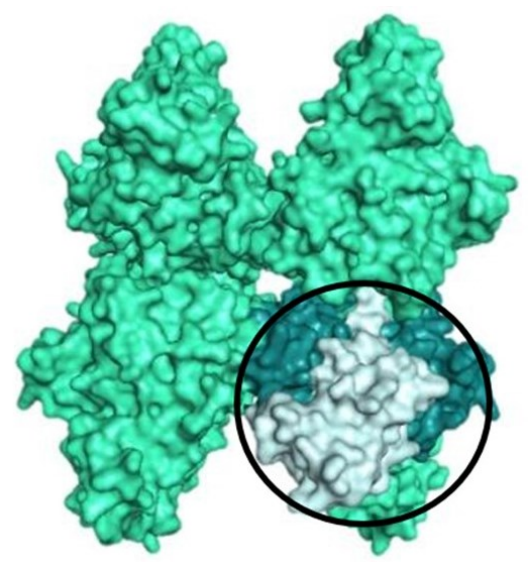

Figura 8: Representación tridimensional de la estructura de ADAM10. En la figura se representa un tetrámero del dominio extracelular de ADAM10. El círculo resalta un monómero. En color azul claro aparece representado el dominio CRD y color azul oscuro aparece representado el dominio metaloproteasa. 
La cola citoplasmática en $\mathrm{C}$ terminal contiene dos regiones ricas en prolina (PRR) que podrían permitir la unión a las proteínas que contienen el dominio SH3. La secuencia N-terminal de la proteasa es necesaria para la maduración intracelular. El dominio de la metaloproteinasa catalítica (aminoácidos 213-456) es el dominio más grande de ADAM10 y puede ser activado por diferentes señales, incluyendo los cambios conformacionales inducidos por el sustrato en la membrana plasmática. La región proximal de la membrana es importante para la adhesión y el reconocimiento del sustrato y contiene un dominio de
desintegración,
uno
rico
cisteína
(aminoácidos
555-673:

NRHTQVCINGQCAGSICEKYGLEECTCASSDGKDDKELCHVCCMKKMDPSTCASTGSVQWSRH FSGRTITLQPGSPCNDFRGYCDVFMRCRLVDADGPLARLKKAIFSPELYENIAEW

(www.uniprot.org)) y uno similar al EGF (Figuras 7 y 8). (Ebsen et al., 2014)

Los sustratos de ADAM10 incluyen proteínas de adhesión, factores de crecimiento, o citoquinas, entre otros, regulando así distintos procesos biológicos. Otros sustratos son el receptor Notch y la proteína precursora de amiloide (APP). ADAM10 es necesaria para un desarrollo embrionario correcto. (Crespo, 2015)

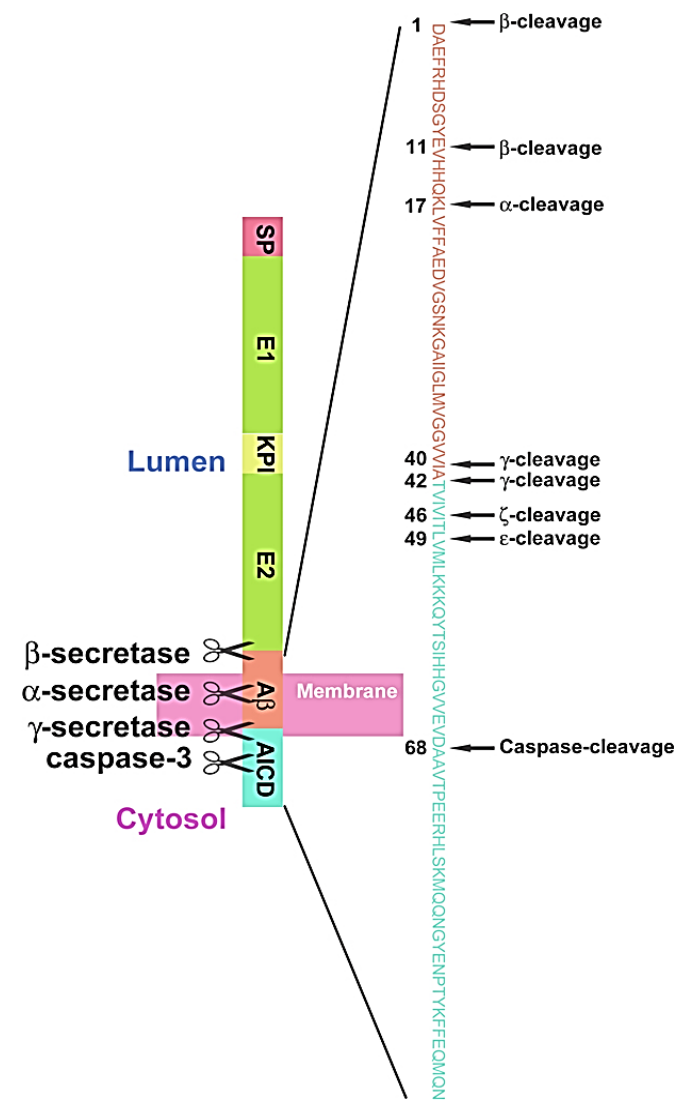

Figura 9: Procesamiento proteolítico de APP. (Zhang et al., 2012)

\section{Corte de ADAM10 en APP}

APP se somete a un procesamiento postraduccional, que involucra varias secretasas y proteasas diferentes, a través de dos vías principales. En la vía no amiloidogénica, APP se segmenta secuencialmente por la $\alpha$-secretasa y la $\gamma$-secretasa. $\alpha$-secretasa (ADAM10), corta APP en el $17^{\circ}$ aminoácido de la secuencia de la Figura 9. (Zhang et al., 2012)

Se conocen pocos reguladores extracelulares de la actividad proteolítica de ADAM10 entre los que se incluyen TIMP1, TIMP3 y SFRP1. Las TIMPs se caracterizan por tener un solo dominio NTR también presente en el extremo C-terminal de SFRP1. SFRP1 se une directamente a ADAM10 regulando su actividad proteolítica. (Crespo, 2015)

\section{Modelo de interacción}

El dominio CRD de SFRP1 puede interaccionar con el dominio CRD de ADAM10. Esta unión acerca el dominio catalítico de ADAM10 al dominio NTR de SFRP1. Como el dominio NTR tiene similitud con los inhibidores TIMP, puede interferir con la actividad enzimática de ADAM10 mediante competición alostérica con diversos sustratos, como APP (Figura 10 y 11A). (Rueda, 2017) 
A

ADAM10

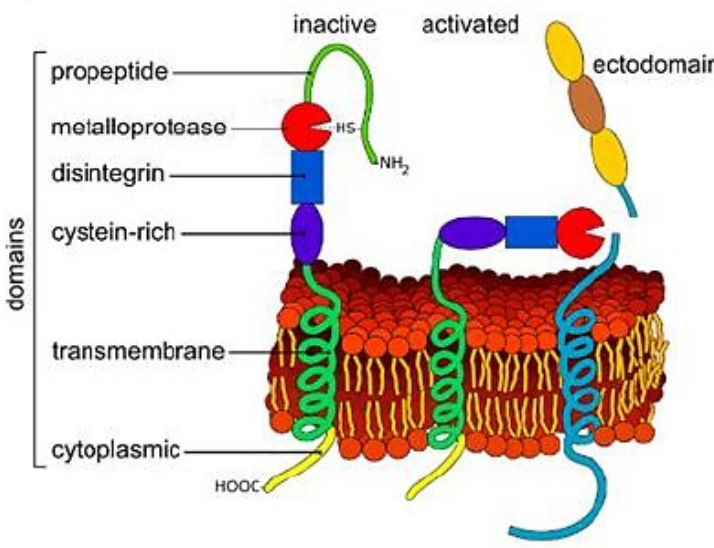

\section{Sfrp1 Negative} modulation

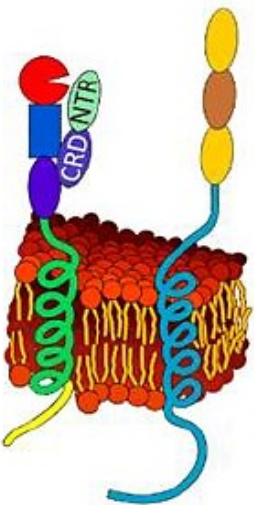

Figura 10: Modelo de interacción entre SFRP1 y ADAM10. (Rueda, 2017)

\section{Objetivo}

Varias inmunoterapias contra el péptido $\beta$-amiloide han dado resultados desalentadores. No obstante, los resultados recientes obtenidos ya sea con la administración de un anticuerpo monoclonal diferente contra $\beta$-amiloide (aducanumab) que ataca las formas oligoméricas tóxicas de $\beta$-amiloide, o con la sustitución de la albúmina plasmática, que elimina los péptidos de $\beta$-amiloide, apuntan al beneficio de disminuir la carga de $\beta$-amiloide.

En los ratones, la neutralización de la SFRP1 da lugar a un mantenimiento eficaz de la función sináptica sin causar una infiltración perjudicial de macrófagos, por lo que la reducción de los niveles de SFRP1 tiene un efecto positivo, al menos cuando se aplica en las primeras etapas de la enfermedad.

Por eso sería bueno aplicar esta posible futura terapia en combinación con métodos novedosos de diagnóstico temprano de la enfermedad.

Así pues, desde un punto de vista especulativo, la aplicación de SFRP1 sola o en combinación con otras estrategias prometedoras contra el péptido $\beta$-amiloide puede representar una vía terapéutica para los pacientes presintomáticos con EA, aunque sigue habiendo una posibilidad de que se produzcan efectos secundarios no deseados. De hecho, SFRP1 actúa en diferentes vías y muchos de los sustratos de ADAM10 están implicados en la formación de tumores y en la inflamación general.

No obstante, estudios recientes han propuesto que la activación moderada de ADAM10 podría ayudar a prevenir la aparición de la EA. El SFRP1 no es un inhibidor completo sino más bien un modulador negativo de ADAM10. (Esteve et al., 2019b).

Por ello, no buscamos un inhibidor completo de SFRP1, sino un inhibidor parcial.

El objetivo del trabajo es conseguir un compuesto que inhiba la interacción entre SFRP1 y ADAM10 parcialmente (Figura 11).

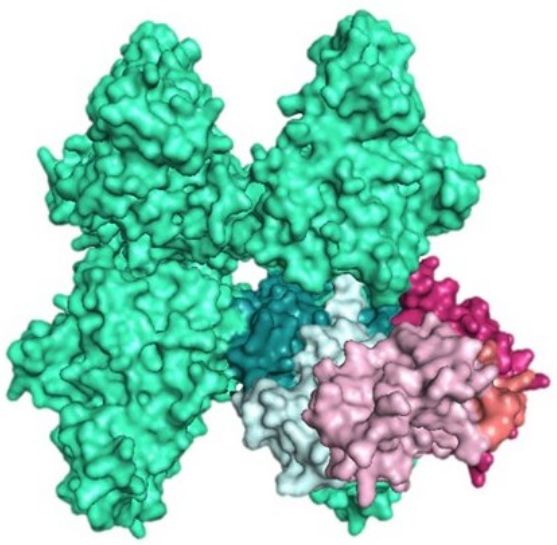

A

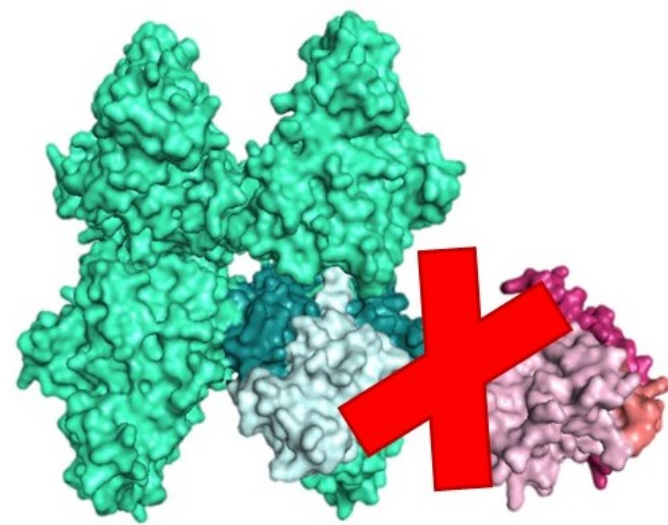

B

Figura 11: Modelo tridimensional de interacción entre SFRP1 y ADAM10. A) Interacción entre SFRP1 y ADAM10. B) Bloqueo de la interacción entre SFRP1 y ADAM10. 


\section{Proceso de "drug discovery"}

El proceso de búsqueda de fármacos o drug discovery constaría de los siguientes pasos: pre-cribado computacional, ensayo HTS, selección de hits con IC-50 más bajo y optimización por modificaciones químicas, estudio del coeficiente de reparto o $\log \mathrm{P}$ y permeabilidad de membrana, ensayo in vitro en células telencefálicas, ensayos in vivo en ratones y ensayo clínico.

\section{Pre-cribado computacional}

Asumimos que somos una empresa farmacéutica que cuenta con una librería de millones de compuestos químicos. Debido a la carga de trabajo que supondría probarlos todos en un ensayo HTS, idealmente se diseñaría un pre-cribado computacional.

En primer lugar, se partiría de librerías de moléculas ya caracterizadas, lo cual nos permitirá reducir los compuestos a estudiar aplicando varios filtros. Nos quedaremos con librerías de compuestos con las siguientes características: a) Capacidad de atravesar la membrana hematoencefálica, ya que se busca un compuesto capaz de pasar de sangre a cerebro, donde queremos que actúe (Pardridge, 2012). b) Que cumpla la regla de los 5 de Lipinski (Benet et al., 2016): estos criterios permiten evaluar cualitativamente cómo de adecuado podría resultar un compuesto químico para cumplir alguna determinada función farmacológica o actividad biológica una vez que es ingerido como medicamento para consumo oral en seres humanos (observación empírica).

En segundo lugar, mediante técnicas computacionales seleccionamos por docking aquellos compuestos capaces de unirse a SFRP1 de forma selectiva teniendo en cuenta los siguientes factores: a) Sitio de unión. Idealmente, nos interesaría encontrar un compuesto químico capaz de unirse al dominio CRD de SFRP1, ya que este dominio hace posible la unión de SFRP1 a ADAM10 (Esteve et al., 2019b). Cabe destacar que un compuesto capaz de unirse al dominio HTR también podría ser de utilidad ya que es responsable del efecto inhibitorio sobre ADAM10. Sin embargo, nos centraremos en inhibir la unión a CRD, pues es más simple: si se inhibe la unión no es posible que SFRP1 inhiba a ADAM10 como se observa en la figura 11. b) Selectividad. También hay que tener en cuenta que aparte de SFRP1, existen otras proteínas con similitud estructural (SFRP2, SFRP3, SFRP4...) (Esteve et al., 2019b), con las cuales SFRP1 comparte cierta homología en cuanto a estructura y secuencia. Nos interesa desarrollar un inhibidor lo más selectivo posible frente a SFRP1, pues si tiene capacidad de inhibir a las otras proteínas anteriores habría un mayor riesgo de efectos secundarios indeseados. Por ejemplo, se ha descrito previamente que la ausencia de Sfrp1/Sfrp2 causa una pérdida de retina periférica y una expansión de la central (Crespo, 2015). Por tanto, en los estudios computacionales se buscarían compuestos que se unan a la región CRD de SFRP1 y que esta unión sea específica solo para SFRP1.

\section{Ensayo HTS}

Realizamos un cribado de los compuestos anteriormente seleccionados mediante un ensayo HTS (Highthroughput screening). Para elegir nuestro compuesto haremos un estudio basado en FRET (Förster resonance energy transfer) con el cual podremos detectar la actividad proteolítica de APP por parte de ADAM10. Para ello ya existen kits comerciales disponibles (Ko et al., 2014).

\section{Esquema del ensayo}

Se trabajará en placas multipocillo para poder testar un gran número de compuestos de forma simultánea. En cada pocillo tendremos los siguientes componentes:

a) Compuesto a testar a una concentración relativamente alta, por ejemplo, de 50 micromolar.

b) SFRP1 en gran cantidad (para asegurarse de que ADAM10 esté bloqueado completamente en ausencia de inhibidores.

\section{c) ADAM10}

d) Sustrato de ADAM10 modificado: péptido secuencia de corte de ADAM10 en APP en cuyos extremos hay unidos un fluoróforo en uno y un quencher en el contrario (ver Figura 12). Así, si ADAM10 no se encuentra inhibida por SFRP1, podrá actuar y cortará su sustrato, partiéndose la estructura quimérica en dos partes, y alejándose el fluoróforo de su quencher, por lo que podremos detectar emisión de luz si el fluoróforo es excitado a una determinada longitud de onda. Conseguir este tipo de sustrato FRET no sería difícil, ya que actualmente se dispone de productos comerciales de este tipo, como es el caso del kit comercializado por AnaSpec, de EGT Group (Ko et al., 2014).

De esta forma, si un compuesto es capaz de unirse a SFRP1 e impedir su unión a ADAM10, este podrá cortar el sustrato y habrá emisión de fluorescencia. A mayor fluorescencia, mayor será la inhibición de Sfrp1. 
A)

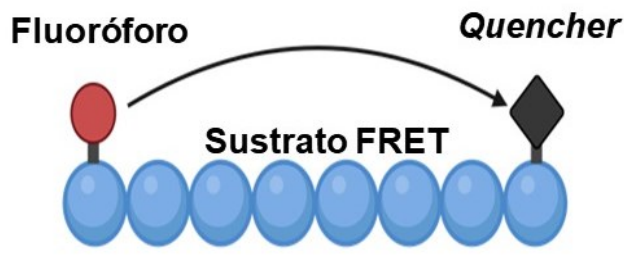

B)

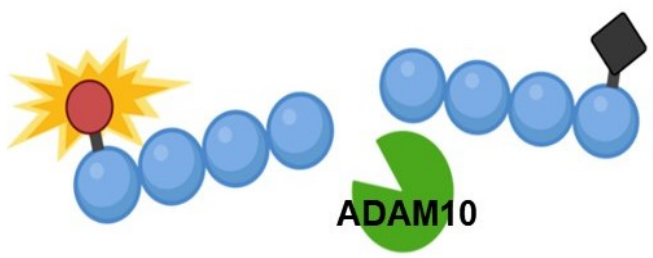

Figura 12. Sustrato FRET modificado utilizado en el ensayo. En la imagen A) se muestra la situación si ADAM 10 está inhibido: no reconoce el sitio de corte del sustrato y, en consecuencia, el fluoróforo se encuentra cerca del quencher y no emitirá fluorescencia. Por otra parte, en la imagen B) se expone la situación si ADAM 10 no está inhibido: se produce un corte en la cadena peptídica y el fluoróforo queda alejado del quencher, por lo que emite fluorescencia susceptible de ser detectada.

\section{Carga de los pocillos}

Como en todo ensayo de evaluación de la inhibición, será necesario contar con controles positivos y negativos, los cuales nos permitirán asegurarnos de que la falta de fluorescencia es por una inhibición de SFRP1 y a su vez, nos permitirán determinar el porcentaje de inhibición de cada compuesto a la concentración testada. Todos los pocillos contarán con lo siguiente:

a) Control positivo: solo se añade ADAM10 y sustrato con fluoróforo.

b) Control negativo: en cada placa usar varios pocillos como control negativo. Tendrán todos los componentes de la reacción excepto el compuesto inhibidor. No se debería detectar fluorescencia en estos pocillos ya que Sfrp1 no estaría inhibida, pero esta sí podría inhibir ADAM10.

c) Compuestos a testar: partiremos con compuestos a una concentración relativamente alta, de 50 micromolar, para seleccionar aquellos compuestos que puedan inhibir parcialmente a SFRP1.

\section{Cálculos para \% inhibición}

Los porcentajes de inhibición serán calculados de acuerdo a la fórmula indicada en la figura 13, comúnmente usado para este tipo de cálculos (Du et al., 2013). Como se puede observar, cuanto mayor sea el nivel de fluorescencia, mayor será el porcentaje de inhibición del compuesto testado.

$$
\% \text { inhibición }=\left(\frac{\text { Fluoresc. fármaco }- \text { Fluoresc. } C-}{\text { Fluoresc. } C+- \text { Fluoresc. } C-}\right) \times 100
$$

Figura 13. Fórmula para el cálculo del \% de inhibición.

\section{Selección de hits con IC-50 más bajo y optimización por modificaciones químicas}

Después de seleccionar aquellos compuestos que más inhiban a Sfrp1, se volverá a realizar un ensayo HTS para cada uno de ellos. Esta vez se utilizarán distintas concentraciones del compuesto para calcular el IC-50, es decir, la concentración del inhibidor a la cual se produce un 50\% de inhibición (Brody, 2018). Un ejemplo de cómo calcularlo se puede encontrar en la figura 14.

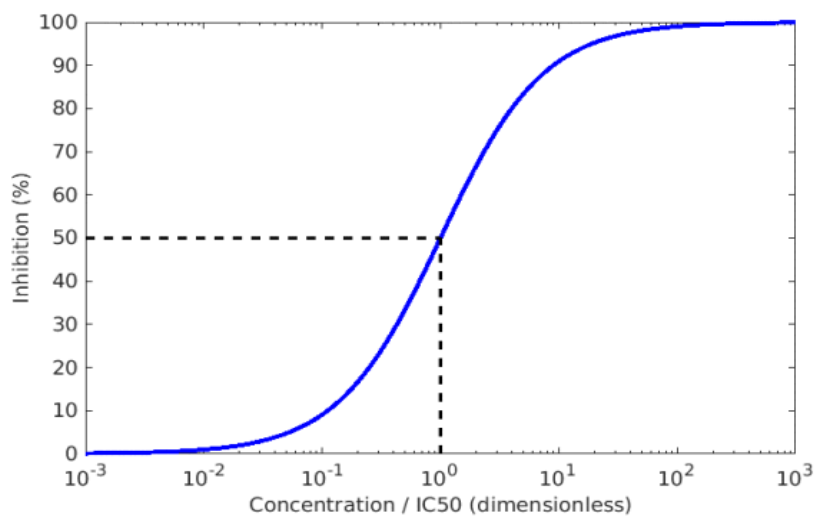

Figura 14. Determinación de IC-50. En la gráfica se representan las distintas concentraciones del compuesto testado frente al porcentaje de inhibición para cada valor de concentración. 
Se seleccionan aquellos compuestos con el menor IC-50, ya que estos serán los más potentes. A partir de estas moléculas se hacen series por modificaciones químicas y se repite el cribado HTS con la finalidad de optimizar las moléculas originales (aumentar potencia, aumentar selectividad.

\section{Estudio del coeficiente de reparto o logP y permeabilidad de membrana}

Con aquellos compuestos seleccionados en la fase anterior, se evalúa el coeficiente de reparto o logP para medir hidrofobicidad y la permeabilidad de los compuestos a membrana mediante ensayos PAMPA (Permeación con Membranas Artificiales en Paralelo) (Saha, 2017).

a) Definimos LogP como el coeficiente con la fórmula indicada en la figura 15:

$$
P=\frac{\text { Fármaco en } n-\text { octanol }}{\text { Fármaco en agua }}
$$

Figura 15. fórmula empleada para el cálculo de $\log P$

Los valores ideales de LogP están en el rango de 1.5-2.7 con un valor medio de 2.1. (Hansch et al., 1977)

b) Con el ensayo PAMPA conseguiremos una buena correlación entre el porcentaje de transporte y la fracción absorbida (Lipinski et al., 2003). Es una técnica que consiste en una membrana lipídica artificial la cual se impregna con un filtro poroso, a través de la cual pasan los compuestos pasan de acuerdo con su permeabilidad aparente (Papp). Los compuestos con Papp inferior a 2,0 × 10-6 cm s-1 se clasificarán como no permeables a la barrera hematoencefálica (-), mientras que los que tenían Papp superior a 4,0 $\times$ 10-6 cm s-1 se consideraron permeables a la barrera hematoencefálica (+) (Bicker et al., 2016).

En nuestro ensayo PAMPA seguiremos un protocolo como el descrito en el artículo de Bicker et al. (2016) el cual permite obtener resultados con una alta correlación con respecto a los estudios de permeabilidad con células, con la ventaja de que además resulta más económico y se consiguen resultados considerablemente reproducibles. Brevemente, el esquema de pasos a seguir sería el siguiente: 1) Extraer lípidos de cerebro de cerdo. 2) Estimar la concentración de lípidos del extracto mediante ensayo de fósforo. 3) Incubar los compuestos con la membrana artificial y obtener Papp mediante la correlación de las características físicoquímicas de compuestos conocidos y una regresión lineal.

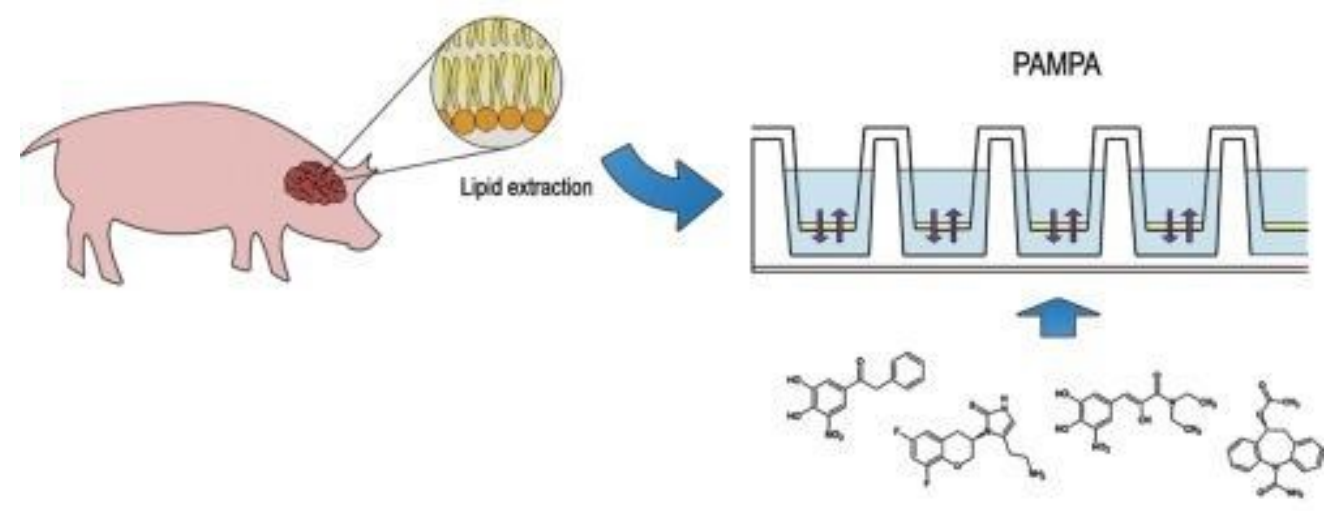

Figura 16. Esquema de ensayo PAMPA llevado a cabo por el grupo de Bicker et al. (2016).

\section{Ensayo in vitro en células telencefálicas}

El proceso de drug discovery continuaría con un ensayo in vitro, el cual nos permitirá confirmar que los compuestos seleccionados realmente son capaces de inhibir a SFRP1. Este ensayo se realizará en concreto con células telencefálicas, las cuales se ha visto que sobreexpresan SFRP1 (Esteve et al., 2019a). A estas células se les añade el compuesto a testar y, paralelamente, se trabaja con un control, que en este caso serían cultivos de células a los que únicamente se les añade el disolvente en el que se encuentran los compuestos testados. Transcurrido un tiempo suficiente de incubación, se haría una extracción proteica de las células $\mathrm{y}$, posteriormente, se realizaría un western blot para detectar la presencia de $\operatorname{sAPP} \alpha$, el producto de APP obtenido por el procesamiento de ADAM10.

Si un compuesto es capaz de inhibir a SFRP1 se esperaría un resultado como el explicado en la figura 17: las células telencefálicas tienen sobreexpresado SFRP1, por lo que ADAM10 siempre se encuentra inhibida y no puede procesar APP a la forma sAPP $\alpha$.Por esta razón, si las células se cultivan con un compuesto capaz de inhibir a SFRP1, ADAM10 podrá ejercer su función y se detectaría la presencia de sAPPaen el western blot. 

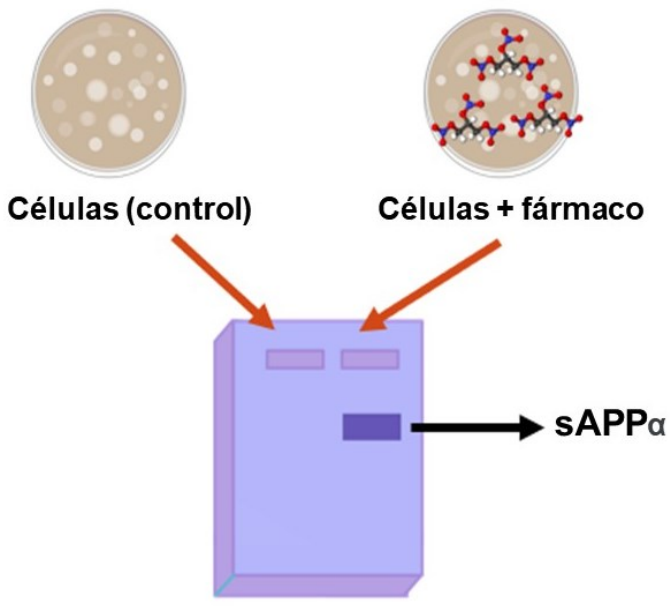

Figura 17. Esquema del ensayo in vitro con células telencefálicas. Tras una incubación de células con el compuesto a testar, se realizar un western blot con anticuerpos anti sAPP $\alpha$. La presencia de la banda correspondiente a SAPP $\alpha$ permite confirmar que el compuesto es capaz de inhibir a SFRP1.

\section{Ensayos in vivo en ratones}

Una vez realizados los ensayos in vitro procederemos a realizar varios ensayos in vivo:

a) Morris Water Maze (MWM) test para evaluar las funciones cognitivas relacionadas con la memoria. Esta prueba consiste en una piscina con cierta profundidad llena de un líquido opaco que dificulte ver la plataforma colocada en su interior. Utilizaremos ratones modelo de Alzheimer (APP; PS1 mice) (Esteve et al., 2019a). El procedimiento que se seguirá será el siguiente: 1) Tendremos tres poblaciones de ratones: control o sanos (WT), enfermos (modelo) y enfermos tratados (ratones a los que se les ha inyectado nuestro tratamiento). 2) Se les entrenará previamente para que encuentren la plataforma (aunque no es un requisito imprescindible). 3) Se les volverá a someter a la prueba y se les evaluará y monitorizará para obtener el recorrido y el periodo de latencia transcurrido hasta encontrar la plataforma.

Los resultados esperados se muestran en la Figura 18. Se espera que el periodo de latencia y recorrido en el grupo de ratones sanos sean mucho menores que en el grupo de ratones enfermos. En cambio, esperamos que en el grupo de ratones enfermos tratados con nuestro fármaco disminuya el periodo de latencia y recorrido con respecto al grupo de ratones enfermos y los valores se acerquen lo máximo posibles a los obtenidos en el grupo control (Figura 18).

A)

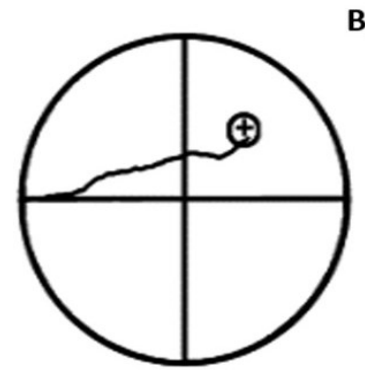

B)

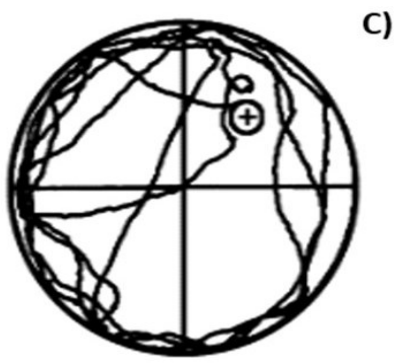

C)

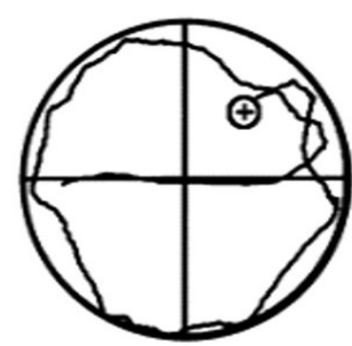

Figura 18: resultados esperados tras la realización del TMW donde se rastrea el recorrido del ratón hasta encontrar la plataforma A. ratones sanos o control, B. ratones enfermos (modelo) y C. ratones tratados con el fármaco. (Oostra and Nelson, 2015).

b) Estudio inmunohistoquímico del péptido $A \beta 42$ utilizando el anticuerpo anti $A \beta 40$. Seguiremos el experimento ya descrito por Esteve et al., (2019a), usando ratones modelo de Alzheimer (APP;PS1 mice), para comprobar si revierte los efectos del Alzheimer. Brevemente, el procedimiento sería como sigue: 1) Tendremos tres poblaciones de ratones: sanos o control (WT), enfermos (modelo) y ratones enfermos tratados con nuestro fármaco potencial durante dos meses. 2) Se les aplicará la eutanasia. 3) Se obtendrán cortes histológicos de cerebros. 4) Se detectará por inmunohistoquímica la presencia de A $\beta 42$ (usando anticuerpos anti-A $\beta 1-40$ ), anticuerpos secundarios y luego con microscopía confocal.

Los resultados que esperamos es que los valores de A $\beta 42$ obtenidos en el grupo de ratones tratados con nuestro fármaco sean menores con respecto al grupo de ratones enfermos y se acerquen lo máximo posible a los obtenidos en el grupo de ratones sanos como se observa en la figura 19. 
A)

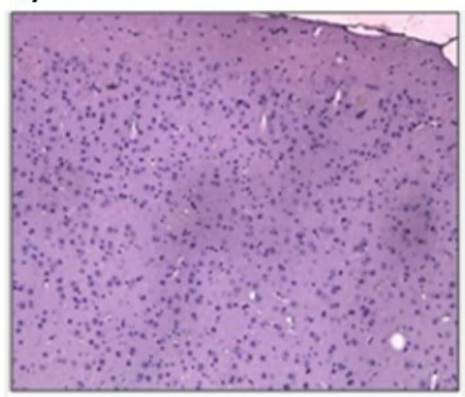

B)

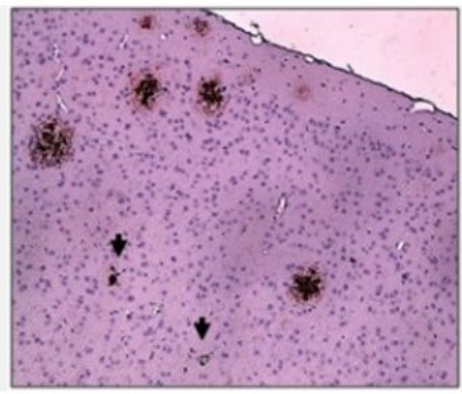

C)

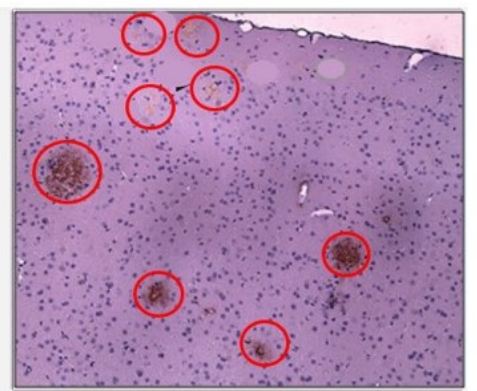

Figura 19. Resultados esperados tras la realización del estudio inmunohistoquímico del péptido $A \beta 42$ utilizando el anticuerpo anti A 440 . En la imagen se observa la aparición de las placas de péptidos $\mathrm{A} \beta 42$ en los distintos grupos de ratones utilizados. En $\mathrm{C}$ se marcan las placas $\beta$-amiloide para indicar la disminución de los niveles del péptido $\mathrm{A} \beta 42$ tras el tratamiento. A. ratones sanos o control, B. ratones enfermos (modelo) y C. ratones enfermos tratados con el fármaco. (Lambracht-Washington and Rosenberg, 2013).

\section{Ensayo clínico}

Si los resultados obtenidos hasta ahora son favorables y, como paso previo a los ensayos clínicos, se procedería a realizar estudios ADME-Tox para aumentar la seguridad, optimización de la dosis empleada para humanos, mejora de la formulación galénica y solicitud de la documentación necesaria a la EMA.

\section{Agradecimientos}

La elaboración de este artículo ha sido posible gracias al apoyo que nos han proporcionado los profesores de la asignatura "Diseño y selección de moléculas biológicamente activas", perteneciente al Máster "Dianas terapéuticas en señalización celular: Investigación y desarrollo" de la Universidad de Alcalá. Queremos agradecer especialmente al profesor Alberto Domingo Galán, quien ha puesto también todo su empeño para poder presentar los resultados de este artículo en el congreso SECUAH 2020, celebrado de forma virtual dada la pandemia de covid-19 en las fechas de su celebración. Los autores del presente artículo estamos deseando poder participar de forma presencial una vez finalice la situación sanitaria actual. Simplemente, gracias por todo.

Tampoco queremos olvidarnos de la doctora Paola Bovolenta, investigadora del Centro de Biología Molecular "Severo Ochoa" de Madrid y experta en la implicación de SFRP1 en el Alzheimer, con varios artículos publicados al respecto en prestigiosas revistas como "Nature neuroscience". A Paola le agradecemos su enorme amabilidad a la hora de resolvernos todas las dudas que tuvimos sobre el tema de estudio. Muchas gracias.

\section{Conflicto de intereses}

Los autores del artículo declaran no tener ningún conflicto de interés.

\section{Bibliografía}

1. Benet, L.Z., Hosey, C.M., Ursu, O. y Oprea, T.I. (2016). BDDCS, the Rule of 5 and drugability. Advanced drug delivery reviews, 101, 89-98. https://doi.org/10.1016/j.addr.2016.05.007

2. Bicker, J., Alves G., Fortuna A., Soares-da-Silva, P. y Falcão, A. (2016). A new PAMPA model using an in-house brain lipid extract for screening the blood-brain barrier permeability of drug candidates. International Journal of Pharmaceutics. 501(1-2), 102-111. https://doi.org/10.1016/j.jpharm.2016.01.074

3. Brody, T., 2018. FDA's Drug review process and the package Label. 1st ed. Cambridge: Academic Press, 441-511.

4. Crespo, I. (2015). Función de Sfrp1 (Secreted Frizzled Related Protein 1) durante el desarrollo de la corteza cerebral y estudio de su posible implicación en la Enfermedad de Alzheimer. Tesis doctoral. Universidad Autónoma de Madrid, Madrid.

5. Hansch, C., Rockwell, S.D., Jow, P.Y.C., Leo, A. y Steller E.E. (1977). Substituent constants for correlation analysis. Journal of Medicinal Chemistry, 20 (2), 304-306.

https://doi:10.1021/jm00212a024 
6. Cummings, J., Lee, G., Ritter, A., Sabbagh, M., Zhong, K. (2019). Alzheimer`s disease drug development pipeline: 2019. Alzheimer's \& Dementia: Translational Research \& Clinical Interventions, 5(1), 272-293. https://doi.org/10.1016/j.trci.2019.05.008

7. Du, Y., Fu, R.W., Lou, B., Zhao, J., Qui, M., Khuri, F.R., y Fu, H. (2013). A time-resolved fluorescence resonance energy transfer assay for high-throughput screening of 14-3-3 proteinprotein interaction inhibitors. Assay and Drug Development Technologies, 11(6), 367-381. https://doi.org/10.1089/adt.2013.507

8. Ebsen, H., Lettau, M., Kabelitz, D. y Janssen, O. (2014). Identification of SH3 Domain Proteins Interacting with the Cytoplasmic Tail of the A Disintegrin and Metalloprotease 10 (ADAM10). PloS one, 9(7), pp. e102899.

9. Esteve, P., Crespo, I., Kaimakis, P., Sandonís, A., \& Bovolenta, P. (2019a). Sfrp1 Modulates Cellsignaling Events Underlying Telencephalic Patterning, Growth and Differentiation. Cerebral Cortex, 29(3), 1059-1074. https://doi.org/10.1093/cercor/bhy013

10. Esteve, P., Rueda-Carrasco, J., Inés Mateo, M., Martin-Bermejo, M. J., Draffin, J., Pereyra, G., et al. (2019b). Elevated levels of Secreted-Frizzled-Related-Protein 1 contribute to Alzheimer's disease pathogenesis. Nature Neuroscience, 22(8), 1258-1268. https://doi.org/10.1038/s41593-019-0432-1

11. Elmaleh, D.R., Farlow, M.R., Conti, P.S., Tompkins, R.G., Kundakovic, L., \& Tanzi, R.E. (2019). Developing effective Alzheimer's disease therapies: Clinical experience and future directions. Journal of Alzheimer's Disease, 71(3) 715-732 . https://doi.org/10.3233/JAD-190507

12. González, A. (2010). Principios de bioquímica clínica y patología molecular: Álvaro González Hernández ( $3^{\circ}$ edición), Barcelona, España: Elsevier.

13. Ko, C.Y., Zhu, M., Gurinovich, O., Li, F., Zhang, R., Zhong, J. y Rakhmanova, V. (2014). FRETbased assays for the detection of amyloid degrading protease activity. Conferencia en Society for Neuroscience.

14. Lambracht-Washington, D., y Rosenberg, R.N. (2013). Advances in the development of vaccines for Alzheimer's disease. Discovery medicine, 15(84), 319-326.

15. Lipinski, C., Lombardo, F., Dominy, B. y Feeney, P. (2003). Experimental and computational approaches to estimate solubility and permeability in drug discovery and development settings. Advanced Drug Delivery Reviews, 46, 3-26. https://doi.org/10.1016/S0169-409X(00)00129-0

16. Moya, M. (2014). Principales hipótesis neurodegenerativas de la Enfermedad de Alzheimer. Trabajo Fin de Grado. Universidad Miguel Hernández, Elche.

17. Oostra, B.A., y Nelson, D.L. (2006). Animal models of fragile X syndrome: Mice and flies. Genetic Instabilities and Neurological Diseases. Second Edition. 175-193.

18. Pardridge, WM. (2012). Drug transport across the blood-brain barrier. Journal of Cerebral Blood Flow and Metabolism. 32(11), 1959-1972. https://doi:10.1038/jcbfm.2012.126

19. Parr, C., Mirzaei, N., Christian, M. y Sastre, M. (2014). Activation of the Wnt/b-catenin pathway represses the transcription of the b-amyloid precursor protein cleaving enzyme (BACE1) via binding of T-cell factor-4 to BACE1 promoter. FASEB Journal, 29(2), 623-635. https://doi:10.1096/fj.14253211

20. Rueda, J. (2017). Sfrp1 promotes neuroinflammation through the modulation of ADAM10 proteolytic activity. Tesis doctoral. Universidad Autónoma de Madrid, Madrid.

21. Saha, S. (2017). Log P. In: Z. Wang, ed., Encyclopedia of Physical Organic Chemistry, 1st ed. Hong Kong, Kowloon: Wiley Inter Sciencie New York, 579-629.

22. UniProt. Disponible en: https://www.uniprot.org/ [Consulta: 13 de febrero de 2020]

23. Zhang, H., Ma, Q., Zhang, Y. y Xu, H. (2012). Proteolytic processing of Alzheimer's $\beta$-amyloid precursor protein. Journal of Neurochemistry, 120, 9-21. https://doi:10.1111/j.14714159.2011.07519.x 